\title{
The Effects of Using Management Information Systems (MIS) on Organizational Structure of the Municipalities in the Province of Khuzestan, Iran
}

\author{
1Sirus Aalipoor \\ 2Majid Nili Ahmadabadi \\ 1Kish International Branch, Islamic Azad University, Iran \\ 2Department of Management, Qom University, Qom, Iran \\ Correspondence: Majid Nili Ahmadabadi (nili2536@gmail.com)
}

Doi:10.5901/mjss.2015.v6n6p477

\begin{abstract}
Running organizations in an efficient way especially in today's complicated world needs gathering and processing a huge amount of information which is growing rapidly. The quality and quantity of the information required by managers for making decisions depend on different factors, but information features and the way they are processed are fundamental factors for making decision in this process. The aim of this research is to study the effects of management information systems (MIS) on the organizational structure. The statistical population in this research includes about 500 senior and junior executives of municipalities of Khuzestan province (Andimeshk, Ahvaz, Masjed Soleyman, Andika and Shooshtar), Iran. However, a sample of 225 managers was selected using Cochran formula and stratified cluster sampling method. To test the hypotheses of the research, structural equation modeling, correlation, and regression were used; Friedman test was also used for rank-ordering the measures. The results showed that management information systems were effective on complexity and formality variables, but the effects of management information systems on centralization were not confirmed. Therefore, systematizing management information systems in the organizations and centralization of decision-making at all management levels lead to reduction in the level of centralization in organizations, increase in horizontal complexity, and reduction in organizational hierarchy.
\end{abstract}

Keywords: Management information systems, Complexity, Formality, Centralization

\section{Introduction}

In today's world, because of the complexity of the problems, the need for information, statics, and figures in making decisions for management is more than before. If there is enough accurate and comprehensive information for management, the risk of making wrong decisions will become less. Therefore, today's organizations should gather, classify, process and analyze different necessary information for management and put them quickly in the hands of administrators. To provide such information, computers are used and management information systems have become much more functional (Nikooyi-Moghadam, 2008). The explosion of information should be considered as the most important industrial incident in twentieth century which has overshadowed the areas of industry. In today's competitive world, information is at the same level of human's capital and power, and they are known as production factors and the best advantage of economic institutions. In this regard, from years ago, management information system (MIS) in industrial countries and in recent years in our country has been the center of attention (Shahbazi \& Ebrahimzadeh, 2007). More than 80 percent of managers' daily work is used for information such as receiving information, communication, and making use of information in a wide range. Inasmuch as the information is the bases of all the activities of an organization, there should be systems which generate and manage information. The aim of such systems is providing security in presenting correct and reliable information whenever needed. Such systems are called information systems. Management information system after gradual evolution in recent five decades have possessed a clear definition, concept and a specified shape and what are being developed, include the technology of implementation, decision making ,and decision support systems (Chen, 2007).

\section{Problem Statement}

Organizational structure is one of the most important and determinant feature of each organization. Using the right 
organizational structure will result in basic improvements in operation for organization. Establishment of an appropriate administrative and achievement of the expected output in existence of desired data and sources, needs factor. The structure of the organization has the most important role in effective function of today's organizations, whether they are small repairing ones or national governments of different countries (Abbasi \& Allahyari fard, 2011). Today, increasing the growth of information technology and its impressive effect in increasing the efficiency of governmental and private organizations around the world, has resulted in a global movement toward exploitation of different information technologies especially management information system. Numerous governmental and private organizations have benefited from management information system and a useful and effective management tool in decision making, but there are more organizations which are deprived of its benefits (Ghazizadeh, 2006). Running organizations in an efficient way especially in today's complicated world needs gathering and processing a large amount of different information which is growing fast. The quantity and quality of the information required by managers for decision making depend on different features, but the features of information itself and the way they are processed are basic factors in this process. Information should not have features such as accuracy, validity, novelty, speed, and etc., but also they should be processed in a way which improves the way the manager makes decision. Therefore, complexity, importance, and the effect of this issue have caused J-galborayt know the organizations as a synonym of information system (Sabzikaran, 2010). Researchers have shown that good instructions for decision making need 90 percent information and 10 percent intuition, and 78 percent of time and 67 percent of managers' working are spent on information and communication. The concept of information is based on the belief that something valuable has been transferred to a person or an organization, therefore; since people resort to multiple data sources and the amount of information and the speed of their generation are growing, having a kind of system which processes, compresses, save, and transfers the information, is necessary. Because of this fact, there is a system of information for managers in organizations which is called management information system (Sarrafizadeh, 2003). Organizational structure is the dominant relation between people and groups who try toward achieving their goals and is divided into two aspects of structure and content. Structural dimensions represent the features within the organization and they produce the foundation based on which measuring and comparing the organizations become possible. The organization's aspect of content includes measure, type of technology, environment and its goals which affects the structural aspect (Hashemi, 2010). Managers' information needs are different based on the nature of the work and their organizational level and their goals. Generally, higher level managers pay less attention to the details of the issue than lower-level managers or experts. In other words, higher-level managers' attitude towards the organization and its duties is much more prevailing than that of lower level managers. Therefore; the information that is put in the hands of such managers should be in harmony with such attitudes. On the other hand, it should be specified that how new management information systems can change organizational structure and executive responsibilities and how new system affects each personnel's job (Mirmasoudi et al. 2012). Therefore, establishment of a useful information system to increase the efficiency and effectiveness of the administrative system, preventing an uncontrolled increase in costs, increasing the effectiveness, decreasing outsourcing and increasing the quality of services with customer oriented approach in public sector, are really important. On the other hand, paying attention to the importance of identifying the organization in designing and settlement of management information systems, in a way that such systems are able to be under its influence as well as affect it, is undeniable (sabzikaran, 2010). Therefore, the main problem in this research is that whether establishment of management information system can affect three dimensions of organizational structure.

\section{Significance of the Study}

Research about structural dimensions of the organization and the level of usage in management information systems as two important studied variables in this research, are the increasing necessity for moving toward the capabilities of organizations. In this movement, awareness and preparedness of senior managers in the introduction to management information systems in order to approach the organizations' goals are really important. Without enough and correct information, organizations will be lost in qualm and the more the complexity of the environment and the speed of changes increase, the more qualm increases and the only thing that can prevent this qualm is information. The thing that can save organizations from this qualm is becoming familiar with management information systems and their effects on structural dimensions of organizations (Ahmadi, 2003). This issue is important because they can keep their long term superiority in competitive arenas with other cities by optimal use of management information systems of organizations such as municipalities which have a wide range of activities. Researchers have found that using management information systems unlike using other management parameters is not transitory. Organizations' usage of management information system is downward from senior managers; therefore, using them requires participation and support of senior managers. 
Every small change in this structure will appear as a big change in lower formations of organizations (Zargar, 2003). Nowadays, using management information systems has become vital and inevitable in the improvement of governmental and nongovernmental organizations' structure such as municipalities. Citizens' expectations, improving organizational efficiency, reducing administrative costs, clarification, citizens' satisfaction, providing desired services, increase in the speed of providing services and eventually promoting social welfare of citizens, have redoubled the importance of the issue for organizations such as municipalities (Bakhtiari, 2014). One of the most important factors in making organizational changes is organizational structure. In fact, organizational structure is the main power of changes and it is a framework for all decisions and organizational processes (Wang \& Ahmad, 2003). Organizational structure which is based on management information can speed up and simplify decision making, and appropriate response to environment and solving the problems. A positive relationship between main elements of organization, coordination between the activities of its different units and clarifying organizational relations in reporting are of the features of organizational structure based on comprehensive management information (Daft, 1991).

\section{Literature Review}

\subsection{Management Information System}

Management information system is a set of related components which aims at gathering, processing, saving and transferring information. This special aim can include a wider range of organizational activities such as making decision, making harmony, controlling, analyzing systems, and producing new productions (Barzegar, 2009). There are two different viewpoints or definitions about MIS. From the first point of view, MIS includes the systems that are shown in Figuren 1 (Doorandish, 2010).

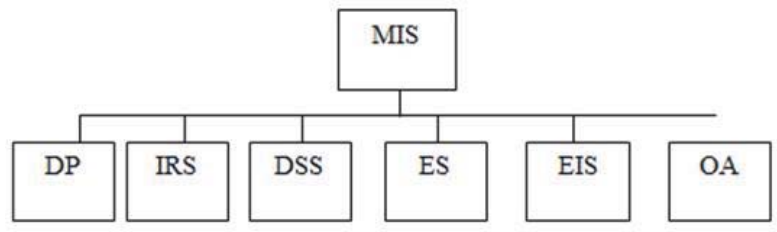

From the second viewpoint, MIS is a kind of information system which can provide special management reports and cover managers' duties especially central managers. By paying attention whether to duties that have been proposed and accepted by the managers of our time or to Fayvl's five duties and by considering manager's different role from Mintzberg's point of view, we can understand that a manager needs useful information in order to do his duties. Therefore, the role of information and transmission information system is really important (Doorandish, 2010).

Management information system subsets are (Rezaeiyan, 2011)

1- Human resource management information systems

2- Financial management and accounting information systems

3- Production management information systems

4- Marketing and sales information systems based on common and mutual bases

The features of management information systems are (Rezaeiyan, 2012).

1- The one that offers detailed information to determiners in its right time, because offering on time and detailed information is one of the main goals of every information system. 2- The one that can answer the needs of management for information. 3- The one that provides the management with reports based on exceptions. 4The one which has the power of merging in future. Power of merging is generally called compatibility. 5- The one that is accepted by the users.

\subsection{Organizational structure}

In investigating the management science column, we are faced with three expressions: organization, organizing, and organizational structure which can be used instead of each other. The organizational structure is the result of organizing and designing the organization and it includes relations, regulations, and rules that even if they are formed unofficially, they are passed officially and form people's activities for achieving common organizational goals. The aim of designing an 
organizational structure is that human resources and existing sources merge together harmonically to result in synergy and efficiency of existing resources (Rezaeiyan, 2011). Dimensions of organizational structure include: 1- Formality: It refers to the level of organizational jobs standards (Robbins, 2008). If the level of formality of the job is high, the worker has the least freedom in fulfilling his duties and the right time to do them. 2-Centralization: It refers to where decisionmaking authority is focused. 3- Complexity: Haal states that complexity is the first thing that a person encounters after entering an organization. This complexity is division of labor, job titles, numerous organizational sections, and different levels that are in the hands of an organization (Haal, 1997). Inasmuch as this research is about the effects of using management information systems on organizational structure, in defining the concept of management information system and organizational structure a conceptual model is used in which the independent variable is management information system and the dependent variable of organizational structure according to Robbins, is focus, complexity and formality (Chen, 2007). By studying the related researches and the literature of the research, the following conceptual model is designed and the relationship between these two variables is shown by the following overview.

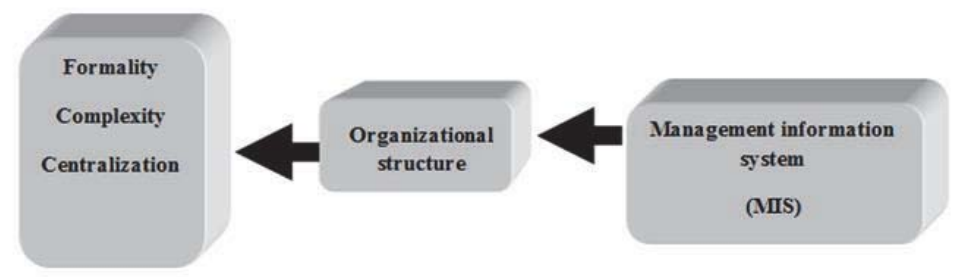

\section{Background of the Research}

The results of the similar previous studies are shown in the following table 1.

Table 1: Domestic and foreign research studies

\begin{tabular}{|c|c|c|c|}
\hline No. & Researcher & Year of the Study & Results \\
\hline 1 & Kazem Mehrabi & 2003 & $\begin{array}{l}\text { There is a positive and meaningful relationship between the dimensions of organizational } \\
\text { structure and using information technology. By raising the level of information technology, the } \\
\text { centralization in an organization raises as well and by increasing the level of using information } \\
\text { technology, the managers' ability to control will be increased and organizational structure will } \\
\text { become more flat. }\end{array}$ \\
\hline 2 & Javad Adineh Safa Sanjani & 1939 & $\begin{array}{l}\text { The results confirm the effect of technology on centralization (increase in centralization) and } \\
\text { decrease in formality and creating more groups in this field. }\end{array}$ \\
\hline 3 & Mohammad Reza Ali Poour & 2009 & $\begin{array}{l}\text { The results show that information technology has a meaningful relation with formality and staff } \\
\text { ratio but not with complexity and relation centralization variables. }\end{array}$ \\
\hline 4 & Zebardast & 2005 & $\begin{array}{l}\text { On time, linked with detailed and real information managing information systems will result in } \\
\text { improvement in managing decisions. }\end{array}$ \\
\hline 5 & Nekooyi Moghadam et. al. & 2007 & $\begin{array}{l}\text { The results show that there is a direct meaningful relation between management information } \\
\text { systems and the centralization variable and there is a meaningful but reverse relationship } \\
\text { between management information systems and the formality variable. }\end{array}$ \\
\hline 6 & Hekmatollah Dastranj & 2008 & $\begin{array}{l}\text { The results reject the relation between information system and centralization, formality, field of } \\
\text { control and organizational pyramid. }\end{array}$ \\
\hline 7 & Javad Adineh Safa Sankani & 2003 & $\begin{array}{l}\text { Studying of the results confirm the effect of technology on centralization (increasing the } \\
\text { centralization) and decrease in formality and the creation of more groups in this field. }\end{array}$ \\
\hline 8 & Garbksny & 2000 & $\begin{array}{l}\text { The results showed that because information technology increases the improvement and } \\
\text { speed in management decision making, they result in centralization and harmony in } \\
\text { organizations. }\end{array}$ \\
\hline 9 & Motohashi & 2001 & $\begin{array}{l}\text { The relationship between management information systems and centralization in decision } \\
\text { making in organizations is confirmed. }\end{array}$ \\
\hline 10 & Mirmasoud et al. & 2012 & $\begin{array}{l}\text { The results confirm the effect of management information systems on complexity, formality, } \\
\text { and centralization variables. }\end{array}$ \\
\hline 11 & Golabzadeh et al. & 2013 & $\begin{array}{l}\text { The results show that creation of clients' trust to this system being useful is simpler. The } \\
\text { variables which explain organizational features, being at hand, commitment, and protection } \\
\text { have the most influence. }\end{array}$ \\
\hline
\end{tabular}




\section{Research Hypotheses}

The major hypothesis: Management information systems are effective on organizational structure of the municipalities of Khuzestan province.

Minor hypotheses:

1- The use of management information systems is effective on the complexity in municipalities of Khuzestan province.

2- The use of management information systems is effective on the formality in municipalities of Khuzestan province.

3- The use of management information systems is effective on the centralization in municipalities of Khuzestan province.

\section{Research Methodology}

The existing research, from its aim point of view, is functional and from its information gathering point of view is a crosssectional survey and its type is correlational. To analyze the data, inferential statistics were used. The statistical population in this research includes about 500 senior and junior executives of municipalities of Khuzestan province (Andimeshk, Ahvaz, Masjed Soleyman, Andika and Shooshtar), Iran. However, a sample of 225 managers was selected using Cochran formula and stratified cluster sampling method.

The method of gathering data in this study is field research and the tool for gathering data is a questionnaire consisting of three sections. The first section is related to demographic items and the second section is related to management information system which includes items related to the literature (Nekooyi Moghadam \& otherscolleagues, 2007; Golabzadeh et al., 2013; Chen, 2007). In the third section, standard questionnaire of Robbins which contains 24 items is used.

\section{Reliability and Validity of Research}

In this research for the validity test, teachers and experts' comments were used and its validity was confirmed. For measuring the reliability of the research, Cronbach alpha coefficient was calculated and showed that the reliability was satisfactory.

Table 2: Reliability of the questionnaire in divisions of dimensions

\begin{tabular}{|l|c|c|c|}
\hline Variable & Reliability coefficient & Dimension & Reliability coefficient dimension \\
\hline \multirow{2}{*}{ Organizational structure } & \multirow{2}{*}{0.927} & Complexity & 0.908 \\
\cline { 3 - 4 } & & Formality & 0.896 \\
\cline { 3 - 4 } & & Focus & 0.840 \\
\hline Management information system & \multicolumn{2}{|c|}{0.908} \\
\hline
\end{tabular}

\section{Data Analysis Method}

In this research, existing techniques in descriptive and inferential statistics are used. In the first stage, analysis of the data that is done by using descriptive statistics expresses the properties of the sample. Then, to test the research hypotheses, structural equation methods, regression, and Friedman test were used.

\section{Data Analysis}

\subsection{Demographic variables of the respondents}

Regarding the gender variable, the obtained results showed that 33.5 percent of the respondents were female, 61.8 percent of them were male, and 4.8 percent had not responded to this item. Moreover, in describing the age variable, 19.1 percent of the respondents were less than 30, 48.2 percent were between 30 to 40, 26.3 percent were between 40 to 50 , and 1.2 percent were between 50 to 60 . Also 5.2 percent had not responded to this item. About the education of the respondents, it was noticed that 2.4 percent of them had diploma, 8 percent had junior college diploma, 75.4 percent 
had BA, and 27.5 percent had MA and MSC. Also 4.8 percent had not responded to this item. About job backgrounds of the respondents, it was noticed that the background of 24.7 percent of them was under 10 years, 40.2 percent between 10 to 15 years, 17.9 percent between 15 to 20 years, and 20 percent were more than 20 years. Also 5.2 percent had not responded to this item.

\subsection{Description of variables}

Table 3 shows the amount of using management information system and its size. The biggest average within the size of the amount of using management information system is related to the process and systems variables.

Table 3: Description of the amount of using management information system

\begin{tabular}{|l|c|c|c|c|c|c|}
\hline & Number & Minimum & Maximum & Average & Standard deviation & Variance \\
\hline The amount of using management information system & 251 & 1.95 & 4.4 & 2.8949 & 0.41857 & 0.175 \\
\hline
\end{tabular}

Table 4: Description of the dimensions of the amount of using management information system

\begin{tabular}{|l|c|c|c|c|c|c|}
\hline & Number & Minimum & Maximum & Average & Standard deviation & Variance \\
\hline Hardware & 251 & 1.5 & 4.5 & 3.0817 & 0.65788 & 0.433 \\
\hline Software & 251 & 1.4 & 4.8 & 2.6371 & 0.61039 & 0.373 \\
\hline Date base & 251 & 1 & 5 & 2.7614 & 0.46858 & 0.22 \\
\hline
\end{tabular}

Tables 5 and 6 show the description of the organizational variable and its size.

Table 5: Description of organizational structure variable

\begin{tabular}{|l|c|c|c|c|c|c|}
\hline & Number & Minimum & Maximum & Average & Standard deviation & Variance \\
\hline Organizational structure & 250 & 2.1 & 5.35 & 3.8474 & 0.48507 & 0.235 \\
\hline
\end{tabular}

In describing the size of organizational structure, it is noticed that the biggest average within the size of organizational structure is related to formality.

Table 6: Description of the dimensions of structural organization

\begin{tabular}{|l|c|c|c|c|c|c|}
\hline & Number & Minimum & Maximum & Average & Standard deviation & Variance \\
\hline Complexity & 250 & 2.43 & 5.57 & 3.8922 & 0.53494 & 0.286 \\
\hline Formality & 250 & 1.71 & 5.43 & 4.1626 & 0.81686 & 0.667 \\
\hline Concentration & 250 & 1.1 & 5.9 & 3.4873 & 0.79213 & 0.672 \\
\hline
\end{tabular}

\subsection{Testing the research hypotheses}

In this research, for testing the main hypothesis, structural equation modeling approach was used and for testing the secondary hypotheses, regression testing was employed. structure.

The main hypothesis: The amount of using the management information system is effective on organizational

According to the model of the research, it can be noticed that the $t$ value between two variables of using management information system and organizational structure equals 4.93 and inasmuch as this amount is located out of the span of (1.96 \& -1.96), this hypothesis is confirmed. According to the standard coefficient, it is also possible to say that the amount of the effect of using management information system on organizational structure is 0.42 . This research is in harmony with the research that Nekooyi Moghadam et al., 2010 and Mirmasoudi et al, 2012, and Chen, 2007 have conducted.

Minor hypotheses:

1) The use of management information systems is effective on the complexity in municipalities of Khuzestan province. 
It is noticed that the level of significance for testing the regression of the first minor hypothesis is less than 0.05 ( $p \leq 0.05$ ); therefore, this effect is significant and the first minor hypothesis is confirmed. As a result, the amount of using management information system is effective on the organizational complexity. The impact of using management information system on organizational complexity is +48.4 percent. According to beta coefficient value, it can be stated that this influence is positive. Also, the coefficient of determination between two variables is 0.234 which shows that the amount of using management information system that is 23.4 , can predict the amount of organizational complexity. This research is in harmony with Nekooyi Moghadam et al., 2007, Mirmasoudi et al, 2012, and Chen, 2007.

2) The use of management information systems is effective on the formality in municipalities of Khuzestan province.

It is noticed that the level of significance for the regression of the second minor hypothesis is less than 0.05 $(p \leq 0.05)$; therefore, the effect is significant and the second minor hypothesis is confirmed. As a result, the amount of using management information system is effective on the organizational formality. The effect of the amount of using management information system on organizational formality is +52.9 percent. According to beta coefficient value, it can be stated that this effect is positive. Also the coefficient of determination between two variables is 0.28 which shows that the amount of using management information system that is 28 percent can predict the organizational formality. This research is in harmony with Nekooyi Moghadam et al., 2007, Mirmasoudi et al, 2012, and Chen, 2007.

3) The use of management information systems is effective on the centralization in municipalities of Khuzestan province.

It is noticed that the level of significance for the regression of the third minor hypothesis is less than 0.05 $(p \leq 0.05)$; therefore, the effect is significant and the third minor hypothesis is rejected. As a result, the amount of using management information system is not effective on organizational centralization. The findings of this part are not in line with Nekooyi Moghadam et al., 2007, Mirmasoudi et al, 2012, and Chen, 2007.

\section{Conclusions and Recommendations}

According to the results of the research, the managers of municipalities of Khuzestan province should pay more attention to the establishment of the management information system in their respective organizations in a way that true and detailed information should be in hand on time to help the increase of centralization on making decision in every aspect of management, decrease in the level of organizational formality, increase in the line complexity, and decrease in organizational hierarchy. It is recommended that municipalities' managers train people in a way that they gather, classify, process, and analyze different information needed for management and put them in the hands of managers. For the optimal and effective use of these systems, the architectural design of information systems and redesign of organizational structure at the same time in a form of a development organizational plan should be distinctive. Moreover, while designing a system in an organization, the managers should be in partnership.

The managers of municipalities, by using management information systems which is capability of the hardware and software, and using them through updating the sources of data due to increasing the speed of achieving information and the speed of answering should pay more attention to their workers' education and training. The managers should enhance their levels of specialized knowledge and skills and their job opportunities, improve each of their workers' skills in relation with organizational information, decrease organizational levels for increasing the speed of transmitting information to their seniors, and increase the level of their control to increase the amount and diversity of information for their junior managers.

Computers and management information systems should increase managers' speed and accuracy in transmitting information to municipalities on time. The managers of municipalities by increasing the level of availability of management information systems for managers and experts increase the amount of functional management information systems so that the formality in an organization will be decreased. Therefore, it is essential that public sector's managers and programmers establish opportunities for increasing the level of usage of this useful management tool by designing and implementing management information systems in organizations and increasing the level of these systems' availability. Decreasing the level of repeated activities and increasing managers' freedom by using management information systems is recommended. It is suggested that managers increase the level of using information in organizations by specializing workers and employing expert and trained people which decreases formality in organizations and increases the power of decision making.

Municipalities should make organizations needless to making large use of documents and formal methods by using 
information systems to decrease the amount of useless relations. Organizations should be the reason of focus in decision making by using management information systems and providing managers by needed information for making special decisions. Organization should provide conditions in which, by establishing a management information system, decision makers who are at the head of organizations make decisions more easily to decrease the number of decision making meetings. It is recommended that the organization senior managers by the help of management information systems increase their relation and power range in recognizing problems and ease of decision making to increase the level of focus in decisions and manipulation of organizers in decisions. Organizers by using management information systems should provide conditions to make needed decisions in changing, describing, analyzing the gathered data, setting budget, evaluating workers' performances, employing and firing personnel of their own section.

\section{References}

Ahmadi,Ali,(2003),IT and Its Function, Tehran, "Towlid-e- Danesh" Publications.

Barzegar ,K.,(2009),Managemaent Information System and Organized Functions,"Etela'at-e- elmi" Publication, Year 24,Number 363,pp 36-41.

Bakhtiari, Hossein, (2009), Necessity and Importance of Management of Knowledge and in the Information Era", The First Conference of the Executive Management

Sbzikarana, Ismael, (2010), Study of the Relation Between Organized Structure and Empowering the Employees in National Company of Distribution of Petroleum Products-the District of Tehran," Management of Improvement" Magazine, Year 2, Number 3.

Doorandish.p, (2010), Study of Structure and Benefits of Management Information, Web Magazine Number 120, pp 21-26.

El Deft, R. (1991), Designing of Organization, Translated by Ali Erabi and Muhamad Erabi,13th Edition, First Volume, pp 33 - 71.

Robins, S., (2008), The Theory of the organization, Translated by Alvae and Danayae Fard,25th Edition, Tehran, Safar-Eshraqi Publicatoin.

Rezayan, Ali, (2011), Managemaent Information System, Samt Publication,11 ${ }^{\text {th }}$ Edition.

Zargar, M. (2003), Principles of IT, Tehran, Behineh Publication, First Edition.

Sarrafi Zad, (2003), Management Information Systems, $9^{\text {th }}$ Edition, Tehran, Bereua of Termeh Publicatioin.

Yari Fard, E. (2011), Najaf,Study of Relevant Patterns of Organized Structures of Knowledge-based Companies, Technology Parks and Improvement Centers Magazine, $8^{\text {th }}$ Year, Number 29, pp 47 - 54.

Qazi Zadeh, S. Z. (2005), Issues and Problems of Establishing and Using Management Information System in Country by Focusing on Humane Obstacles at Governmental Organizations, Second Conference of IT and Improvement.

Richard, H. (1997),"Organization,structure,process and results", Translated by Ali parsian and Muhamad erabi, Tehran; culture-related researches office.

Sadat-Hashemi, Z, (2010), Study of Strategies of Distinctions and the Minimum of Expenses and Its Effect on the Organization Structures, M.A. Thesis of "Media Management.

Nekooyar Moqadam ,M., Hassan zadeh, Ali. Feyz abadi, V.,( 2008),Study of Relation between Settlement of Management Information Systems and Organized Structures of Governmental Offices in Kerman City, Health Information Management, $5^{\text {th }}$ Period, First Number.

Chen, C.J. (2007), Information Technology, Organizational Structures and News Product Developments---The Meditating Effect of Cross-Functional Team Interaction Engineering Management, IEEE on Volume 54, no 4, pp 687 - 698.

Mirmasoudi A. Farjami Y. Pourebrahimi. A (2012), The Effect of IT on Organizational Structures, International. International Journal Information, Security and Management, Volume 1, Number 2, pp $48-54$. 